\title{
Incidental Thyroid Carcinoma
}

\author{
Nikhil Nanjappa - Abhilash Kumar · Sudeepta Kumar Swain · \\ T. Tirou Aroul - S. Robinson Smile - Dhananjay Kotasthane
}

Received: 11 May 2012/ Accepted: 8 November 2012/Published online: 27 November 2012

(C) Association of Otolaryngologists of India 2012

\begin{abstract}
Objective: to find out the frequency of incidental thyroid carcinoma (ITC) in patients presumably operated for benign thyroid diseases. Methods: a total of 187 patients undergoing surgery for benign thyroid diseases were included in the study. All the patients underwent fine needle aspiration cytology (FNAC). Only those with benign diseases on FNAC were studied. Patients with undetermined cytology and follicular neoplasm were excluded. Results: Out of the 187 patients operated histology revealed ITC in $38(20.3 \%)$ of patients. The mean size of the nodule was $4.28 \pm 1.48 \mathrm{~cm}$ in benign group and $4.21 \pm 1.98 \mathrm{~cm}$ in ITC group. Papillary carcinoma was the commonest ITC $(97.4 \%)$ and follicular variant $(16 / 38)$ was found more often than micropapillary variant $(3 / 38)$. ITC was more common in patients with solitary nodule, 23 of $38(60.5 \%)$, although it wasn't statistically significant $(P$ value 0.262$) 0.33$ of $38(86.8 \%)$ were in euthyroid state
\end{abstract}

\footnotetext{
N. Nanjappa $(\bowtie) \cdot$ A. Kumar $\cdot$ S. K. Swain .

T. T. Aroul - S. R. Smile

Dept of Surgery, Mahatma Gandhi Medical College \&

Research Institute, Pondicherry 607402, India

e-mail: drnikhilnanjappa@gmail.com

\section{A. Kumar}

e-mail: dr.k.abhilash@gmail.com

S. K. Swain

e-mail: sudeeptapappu@ rediffmail.com

T. T. Aroul

e-mail: aroulfrenchie@yahoo.com

S. R. Smile

e-mail: srsmile@yahoo.com

D. Kotasthane

Dept of Pathology, Mahatma Gandhi Medical College \&

Research Institute, Pondicherry 607402, India

e-mail: dr.d.kotasthane@yahoo.com
}

( $P$ value 0.029 ). Conclusions: the result of this study show, a high frequency of ITC (20.3\%). ITC was more frequent in euthyroid patients ( $P$ value 0.029$)$. Incidence of ITC is not significantly different between patients presenting with SNG from those with MNG ( $P$ value 0.262$)$. Papillary carcinoma was the commonest ITC (97.4\%) and follicular variant $(16 / 38)$ was found more often than micropapillary variant $(3 / 38)$.

Keywords Benign thyroid disease . Incidental thyroid carcinoma

\section{List of Abbreviations \\ MNG Multi-nodular goitre \\ SNG Solitary nodular goitre \\ ITC Incidental thyroid malignancy \\ FNAC Fine needle aspiration cytology \\ $95 \%$ CI $95 \%$ confidence interval}

\section{Background}

The term "incidental" denoted malignant tumors of the thyroid gland detected by post-operative biopsy of surgical specimens resected for benign disease. The incidence of ITC ranges from $3-16 \%$ in different series. Among the incidental thyroid malignancies, papillary carcinoma is the commonest pathological type. Micropapillary variant is the most common subtype among papillary carcinoma as described by many studies. Although it is traditionally considered that the incidence of ITC is higher in solitary nodular goiter (SNG) compared to multi-nodular goiter (MNG), it is not significantly different. Thus multinodularity doesn't seem to be a certain indicator of benign 
thyroid disease. ITC is found more often in euthyroid patients, although a hyper functioning thyroid cannot be considered be considered a protective factor against differentiated thyroid carcinoma.

\section{Patients and Methods}

From January 2006 to March 2012, the data from consecutive patients affected with thyroid disease were collected. All patients with fine needle aspiration cytology (FNAC) positive for benign thyroid disease and operated were included. Inconclusive, follicular nodules as well as patients with cytological and clinical evidence of malignancy were excluded. A total of 187 patients, who had undergone FNAC of the dominant nodule after a complete clinical examination revealing benign thyroid disease were included. Surgical operations performed were hemi, subtotal, near, or total thyroidectomy. Significance of mean age, thyroid profile, type of nodular goiter and size of the nodule were evaluated by Chi square test.

\section{Results}

Among the 187 cases of benign thyroid diseases operated, histopathology examination revealed incidental thyroid carcinoma (ITC) in 38(20.3\%) patients (Table 1).

When the two groups, namely benign diseases and ITC were compared, the mean age and the size of the nodule did not show any statistical significance. The mean size of the nodule was $4.28 \pm 1.48 \mathrm{~cm}$ in the benign group and $4.21 \pm 1.48 \mathrm{~cm}$ in the ITC group. Colloid nodule was the commonest on FNAC, 135 of 187 and papillary carcinoma was commonest among ITC (97.4\%) (95\%CI: 86.5199.53) (Table 2) and follicular variant (16/38) was found more often than the micropapillary variant $(3 / 38)$.

While considering the type of goiter, the solitary thyroid nodule (STN) had higher incidence of ITC (23/38) compared with MNG and diffuse goiter, although it wasn't significant ( $P$ value 0.262 ). ITC was more common among the euthyroid patients. Out of the 38 patients with ITC, 30 $(90.9 \%)$ were euthyroid with a $P$ value of 0.029 (Table 3 ).

Table 1 ITC related to preop diagnosis

\begin{tabular}{lllll}
\hline $\begin{array}{l}\text { PRE OP } \\
\text { DIAGNOSIS }\end{array}$ & No. $(\%)$ & $\begin{array}{l}\text { ITC No. } \\
(\%)\end{array}$ & $\begin{array}{l}\text { ITC/187 } \\
(\%)\end{array}$ & $P$ value \\
\hline MNG & $77(41.2)$ & $14(36.9)$ & 7.5 & 0.543 \\
STN & $\mathbf{9 8}(\mathbf{5 2 . 4 )}$ & $\mathbf{2 3}(\mathbf{6 0 . 5})$ & $\mathbf{1 2 . 3}$ & $\mathbf{0 . 2 6 2}$ \\
Diffuse & $12(6.4)$ & $1(2.6)$ & 0.5 & 0.286 \\
Total & 187 & $38(100)$ & 20.3 & - \\
& $(100)$ & & &
\end{tabular}

Bold values indicate the highest number of patients
Table 2 Histology of ITC

\begin{tabular}{lcl}
\hline TYPE & No. $(\%)$ & $95 \%$ CI \\
\hline Papillary & $\mathbf{3 7}(\mathbf{9 7 . 4 )}$ & $\mathbf{8 6 . 5 1 - 9 9 . 5 3}$ \\
Follicular & $1(2.6)$ & $0.05-13.49$ \\
Total & $38(100)$ & - \\
\hline
\end{tabular}

Bold values indicate the highest number of patients

Hemi-thyroidectomy was performed in $90(48.1 \%)$, sub-total thyroidectomy in 91 (48.7\%), near-total thyroidectomy in four $(2.1 \%)$ and total thyroidectomy in two $(1.1 \%)$ patients. Total thyroidectomy was planned on table as in these patients lymph nodes were seen in the pretracheal region. Final histology was papillary carcinoma. Intra-operative finding of lymph node presence was significant in the diagnosis of ITC.

\section{Discussion}

The term "incidental" denotes malignant tumors of the thyroid gland detected by postoperative biopsy of surgical specimens resected for benign disease. The incidence of ITC ranges from 3-16\% in different series. Miccoli et al. [1] found in their study of 104 patients, $10.4 \%$ of ITC. In an autopsy study by, Harrach et al. [2], the incidence ranges from 3-36\%. In other studies, familial thyroid carcinoma was found in 2-24\% of patients operated for a presumably benign thyroid disease [3, 4]. In our study, ITC was diagnosed in $20.3 \%$ of patients. FNAC was not ultrasound guided and only the dominant nodule was aspirated perhaps these were the reason for the high incidence.

Our findings suggest that age, sex and size of the nodules are not indicators of carcinomas. Similar observations have been reported in other studies also. In this series, $97.4 \%$ (95 \%CI: 86.51-99.53) were papillary carcinoma. In a study by Miccoli et al. [1], 95.2\% of patients presented with papillary carcinoma. Papillary carcinoma was found to be the commonest ( $75 \%$ ) in a series by Memon et al. [5] and micropapillary variant was more common [6]. But in our series we found that the follicular variant (16/38)

Table 3 ITC related to thyroid profile

\begin{tabular}{llll}
\hline Thyroid profile & No. $(\%)$ & ITC no. $(\%)$ & $P$ value \\
\hline Hypothyroid & $28(15.0)$ & $1(2.6)$ & $0.017^{*}$ \\
Hyperthyroid & $23(12.3)$ & $4(10.6)$ & 0.709 \\
Euthyroid & $\mathbf{1 3 6}(\mathbf{7 2 . 7})$ & $\mathbf{3 3}(\mathbf{8 6 . 8})$ & $\mathbf{0 . 0 2 9 *}$ \\
Total & $187(100)$ & 38 & - \\
\hline
\end{tabular}

* Statistically significant

Bold values indicate the highest number of patients 
was found more often than micropapillary variant (3/38) on histopathology.

A study by Gelmini et al. [7] analyzing ITC in MNG and STN demonstrated that in the first group, there were $12.6 \%$ and in the second $6.8 \%$ with a $P$ value of $<0.002$. In another study from USA, the incidence of carcinoma in MNG was not significantly different from carcinoma in STN [3]. Koh [8] from Malaysia reported $7.5 \%$ patients with MNG had carcinoma. Traditionally, it is considered that incidence of carcinoma is higher in solitary cold nodule [9]. But multinodularity cannot be considered as a certain indicator of benign thyroid disease [10]. In MNG, there is a possibility of performing FNAC on a benign nodule, hence the need to select a nodule on the basis of vascularity and sonographic features.

ITC was more prevalent in STN $(60.5 \%)$ and in euthyriod patients ( $P$ value 0.029$)$ in our series. Gelmini et al. [7] found no significant difference in the incidence among euthyroid and hyper functioning thyroid patients. Reports in large published studies also say that the difference is not significant [11, 12]. While in some series higher incidence ITC was found in toxic goiters therefore, hyperthyroidism cannot be considered a protective factor against differentiated thyroid carcinoma [1].

Intraoperative findings of lymph nodes in the neck points to carcinoma and two of our cases, though FNAC was benign, total thyroidectomy was carried out and histopathology proved to be papillary carcinoma on histology. We do not consider it as particularly significant since the number is very small.

The finding of this study favors a more radical aggressive therapeutic management in patients with presumably benign thyroid disease, though this remains a controversial issue. The advantages of near-total or total thyroidectomy include reduction of recurrence rate, the avoidance of rare possibilities of transformation from well differentiated to undifferentiated carcinoma, avoidance of second operation, better postoperative monitoring by scintigraphic scan and thyroglobulin measurement, and the increase of the yield of postoperative radio iodine therapy [13]. The disadvantage of total thyroidectomy may be lifelong replacement therapy. Patients who undergo limited resection may also require replacement therapy with Levothyroxine for a shorter period and even if prolonged does not lead to any substantial degradation in the performance and quality of life [6].

This study shows the frequency of ITC is significant in patients operated for benign thyroid disease, being more common in patients who are euthyroid. Also, the incidence of ITC is not significantly different between patients presenting with SNG and MNG. FNAC is fairly inconclusive and suggests that FNAC be performed under ultrasound guidance and multiple aspirations be done in patients with MNG. However, a larger study is needed to draw definite conclusions.

Acknowledgments Authors' would like to acknowledge Mr. Suresh $\mathrm{KP}$ for lending his expertize towards statistical analysis. Authors acknowledge the immense help received from the scholars whose articles are cited and included in references of this manuscript. The authors are also grateful to authors/editors/publishers of all those articles, journals and books from where the literature for this article has been reviewed and discussed.

Conflict of Interests The authors declare no conflict of interests and have not received any source of funding.

\section{References}

1. Miccoli P, Michele N, Minuto et al (2006) Incidental thyroid carcinoma in a large series of consecutive patients operated on, for benign thyroid diseases. ANZ J Surg 76:123-126

2. Harach HR, Franssila KO, Wasenius VH (1985) Occult papillary carcinoma of the thyroid. A "normal" finding in Finland. A systemic autopsy study. Cancer 56:531-538

3. McConahey WM, Hay ID, Woolner LB, Van Heerden JA, Taylor WF (1986) Papillary thyroid cancer treated at the Mayo Clinic. 1946 through 1970: initial manifestation, pathologic findings, therapy and outcome. Mayo Clin Proc 61(97):48-96

4. Fink A, Tomlinson G, Freeman JL, Rosen IB, Asa SL (1996) Occult micro-papillary carcinoma associated with benign follicular thyroid disease and untreated thyroid neoplasms. Mod Pallid 9:816-820

5. Memon W, Khanzadaa TW, Jamad A, Kumar B (2010) Incidence of thyroid carcinoma in multi-nodular goiter. Rawal Med J 35(1):65-67

6. Sakorafas GH, Giotakis J, Stafyla V (2005) Papillary thyroid micro-carcinoma. A surgical perspective. Cancer Treat Rev 31: 423-438

7. Gelmini R, Franzoni C, Pavesi E, Carby F, Saviano M (2010) Incidental thyroid carcinoma (ITC): a retrospective study in a study of 737 patients treated for benign disease. Ann Ital Surg $81: 421-427$

8. Koh KBH, Chang KW (1992) Carcinoma in multi-nodular goiter. Br J Surg 79:266-267

9. Mc Call A, Jarosz H, Lawrence AM, Paloyan E (1986) The incidence of thyroid carcinoma with solitary cold nodules and in multi-nodular goiter. Surgery 100:1128-1132

10. Pelizzo MR, Toniato A, Piotto A, Bernatte P (1996) Cancer in multinodular goiter. Ann Ital Chir 67930:351-356

11. Rgeski MT, Gharib H (1985) Nodular thyroid disease. N Eng J Med 313:428-436

12. Fernando R, Mettenanda DSG, Kariyakarawana J (2009) Incidental occult carcinoma in total thyroidectomy for benign diseases of the thyroid. Ceylon Med J 54(1):4-6

13. Sto Y, Yamoda C, Uruno T et al (2004) Papillary microcarcinoma of the thyroid: how should it be treated? World J Surg 1115:121 